\title{
Goldenes Zeitalter der Stagnation?
}

\author{
Perspektiven auf die sowjetische Ordnung der Breznev-Ära \\ Hrsg. v. Boris Belge u. Martin Deuerlein
}

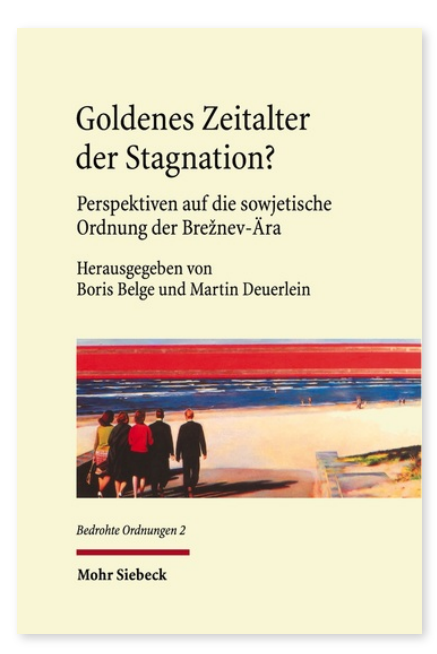

2014. X, 329 Seiten. BedrO 2

ISBN 978-3-16-153003-6 DOI 10.1628/978-3-16-153003-6 eBook PDF 74,00€

ISBN 978-3-16-152996-2

Festeinband $74,00 €$
Die Amtsjahre Leonid I. Brežnevs prägte ein Widerspruch: Auf der einen Seite wollte die politische Führung durch »Vertrauen in die Kader « und eine »Politik der Normalität« nach Nikita Chruščevs sprunghafter Politik eine neue Phase der Stabilität und Berechenbarkeit einläuten. In der Erinnerung vieler sowjetischer Bürger gilt die Brežnev-Ära darum rückblickend als »Goldenes Zeitalter « mit steigendem Lebensstandard.

Auf der anderen Seite fand sich die sowjetische Gesellschaft in einer Phase beschleunigten sozialen Wandels wieder. Zeitgleich versagten Legitimationsmuster, ökonomische Steuerung und politische Entscheidungsfindung in einem solchen Maße, dass die Reformbedürftigkeit der sowjetischen Ordnung allzu deutlich wurde und sich Ende der 1970er Jahre eine Kommunikation über ihre Defizite und mögliche Alternativen etablierte. Die Antwort der Brežnev-Führung war eine noch stärkere Selbstvergewisserung: Für die eigene Stabilität und Normalität nahm sie ein eingeschränktes Sichtfeld in Kauf. Der Sammelband thematisiert die für die sowjetische Ordnung dieser Zeit prägende »Hyperstabilität« in Fallbeispielen zu Großprojekten, stadtplanerischen Projekten, Dissidenten, Künstlern und außenpolitischen Experten. Der Band fragt nach Spezifika der Brežnev-Ära, zeigt neue Forschungsperspektiven auf und setzt sich kritisch mit ihrer traditionellen Bewertung als »Zeitalter der Stagnation« auseinander. Seine Perspektive auf die Wechselverhältnisse von internen Prozessen und transnationaler Verflechtung leistet einen Beitrag zum neu erwachten Interesse an den 1970er Jahren als einer Periode tiefgreifenden sozialen Wandels in West und Ost.

\section{Inhaltsübersicht}

Boris Belge/Martin Deuerlein: Einführung: Ein goldenes Zeitalter der Stagnation? Neue Perspektiven auf die Brežnev-Ära Esther Meier: Brežnevs Ingenieure: Das Großprojekt KamAZ/Naberežnye Čelny - Ivo Mijnssen: Heldenkult und Bringschuld. Hyperstabilität in der Heldenstadt Tula unter Brežnev - Evgenij Kasakow: Das Wiederaufkommen der linken oppositionellen Gruppen in der späten Brežnev-Zeit - Tobias Rupprecht: Schreibtischrevolutionäre. Die meždunarodnki als Bannerträger des sozialistischen Internationalismus in der späten Sowjetunion - Malte Rolf: Die Nationalisierung der Sowjetunion: Indigenisierungspolitik, nationale Kader und die Entstehung von Dissens in der Litauischen Sowjetrepublik der Ära Brežnev Ada Raev: Parallelwelten: Die offizielle und die inoffizielle Kunst in der Brežnev-Ära - Stefan Guth: Stadt der WissenschaftlichTechnischen Revolution: Ševčenko, Kasachstan - Ingo Grabowsky: »Er richtet sich besonders an die janz Scharfen«. Der sowjetische Schlager in den 1960er und frühen 1970er Jahren - Moritz Florin: »Bei uns gab es keine Dissidenten«. Kritik und Dissidenz an der zentralasiatischen Peripherie, 1964-1982 - Klaus Gestwa: Zwischen Stagnation und Perestrojka: Hyperstabilität, Bedrohungskommunikation und der Untergang der Sowjetunion

Boris Belge Geboren 1985; Studium der Neueren und Neuesten Geschichte mit einem Schwerpunkt auf osteuropäischer Geschichte in Tübingen; seit 2010 Wissenschaftlicher Mitarbeiter am Institut für Osteuropäische Geschichte und Landeskunde der Universität Tübingen.

Martin Deuerlein Geboren 1983; Studium der Neueren und Neuesten Geschichte in Tübingen, Sevilla und Yale; seit 2011 ist er Wissenschaftlicher Mitarbeiter am SFB 923 »Bedrohte Ordnungen« an der Universität Tübingen.

Jetzt bestellen:

https://mohrsiebeck.com/buch/goldenes-zeitalter-der-stagnation-9783161530036?no_cache=1

order@mohrsiebeck.com

Telefon: +49 (0)7071-923-17

Telefax: $+49(0) 7071-51104$
Mohr Siebeck GmbH \& Co. KG

Postfach 2040

D-72010 Tübingen

info@mohrsiebeck.com

www.mohrsiebeck.com 